\title{
A Study on the Effect of Perceived Emotional Intelligence of Members on Self-Efficacy and Job Satisfaction
}

\author{
Eun-Ock Choi, Ph.D.student, Dept. Of Knowledge Service \& Consulting, Hansung University, Seoul, South \\ Korea,ceo915@naver.com \\ Yen-Yoo You, Professor, Dept. Of Division of Smart Management Engineering, Hansung University, Seoul, \\ South Korea, threey0818@hansung.ac.kr \\ In Chae Park, Professor, Dept. Of Division of Smart Management Engineering, Hansung University, Seoul, \\ South Korea,ipark@hansung.ac.kr \\ *Hyun Sung Park, Professor, Dept. Of Knowledge Service \& Consulting, Hansung University, Seoul, South \\ Korea, hyunsung.park@hansung.ac.kr \\ *Corresponding Author
}

\begin{abstract}
Emotional intelligence is affecting all parts of the workplace and plays an important role in the organization. In this study, we would like to confirm the effects of emotional intelligence on self-efficacy and job satisfaction that members perceive.

In this study, an online questionnaire was conducted for members of medical institutions in Gyeonggi Province (excluding doctors) to test the hypothesis. The measurement used a Likert 5-point scale and the measurement items consisted of a total of 31 questions. The statistical analysis was performed using technical statistical analysis, exploratory factor analysis, reliability analysis, correlation analysis, and regression analysis using SPSS 22.0.

The results of the study are First, in the influence of the emotional intelligence of the members on the selfefficacy, the negative effect of self-emotion appraisal appeared, the influence of other's emotion appraisal did not appear, and the regulation of emotion and use of emotion were significant. This can confirm the tendency of an individual's beliefs and levels of immersion to achieve goals, etc. to fall when there is insufficient understanding of one's own feelings and others' feelings. On the other hand, it was confirmed that members who actively reflect emotion control and emotion use have their own confidence in determining and performing the choice and intensity of necessary actions. Second, the effects of emotional intelligence on job satisfaction of members showed negative effects on self-emotion appraisal, and positive effects on other's emotion appraisal, regulation of emotion, and use of emotion. Third, it was confirmed that self-efficacy also had a high impact on job satisfaction.

This study will be meaningful in examining the organization from a long-term perspective to vitalize the organization by utilizing emotional intelligence of medical institution members and finding solutions for organizational improvement.
\end{abstract}

Keywords: Emotional Intelligence, Self-efficacy, Job Satisfaction, Self-Emotion Appraisal, Other's Emotion Appraisal, Medical Institutions

Received: 04.12.2020 $\quad$ Accepted: 18.01.2021 $\quad$ Published: 07.02.2021

\section{INTRODUCTION}

Today, the business environment of medical institutions is very competitive for survival, and the needs of customers continue to increase. In this environment, we strive to provide the best medi cal services for the satisfaction and stability of our customers. In order to survive in the era of infinite competition, the most important situation is to enhance management efficiency and increa se organizational performance, and further, the survival of the organization. Therefore, medical in stitutions are making great efforts to study and promote the growth directions of various organiz ations. A medical institution organization is a professional organization in which all tasks are lin ked to the work characteristics of direct customer-facing business. The members of the medical $\mathrm{i}$ nstitution's organization consist of a variety of professional occupations and have a different sens e of achievement and job satisfaction. The most important thing in organizational management is whether or not the members are satisfied with their jobs, which shows that the higher the leve 1 of satisfaction they have with their jobs, the higher the productivity and efficiency of their orga nizations. In the service industry, identifying and accepting various preferences, preferences, and values of individuals has become essential, and it has been studied as a very important factor in 
organizational management to understand customers more quickly and accurately, satisfy custom ers, and effectively achieve change or innovation along with the performance of the organization.

Members' emotional intelligence is affecting all parts of the workplace and plays an important $r$ ole in the organization in important job-related relationships in the field. In this study, we also want to see how emotional intelligence that members perceive affects their self-efficacy and job satisfaction. It is necessary to conduct extended research on members of medical institutions to $t$ he emotional dimension of members, which was limited to cognitive dimensions. Therefore, resea rch between emotional intelligence, self-efficacy and job satisfaction of members of medical instit utions will be a meaningful study.

\section{Theory and formula \\ Emotional Intelligence}

Emotional intelligence is the ability to synchronize individuals in frustrating situations, to protect themselves, to maintain the satisfaction of controlling impulses, to control emotions, to not lose rational thinking in moods or stress situations, to empathize with others, and not give up hope [1]. Representatively, the concept of emotional intelligence was first used by Salovey \& Mayer's research, a series of techniques assumed to contribute to accurately assessing and expressing the emotions of oneself and others, effectively controlling the emotions of oneself and others, and Refers to using emotions to motivate, plan, and achieve in your life [2]. As sub-factors of emotional intelligence, it can be explained through the understanding of self-emotion appraisal and other's emotion appraisal, and regulation of emotion and use of emotion [10].

\section{Self-efficacy}

Self-efficacy is an individual's belief in their ability to perform a given task, and is his or her own confidence in determining and performing the level of goals, level of immersion to achieve them, choice and intensity of necessary actions [3]. It is also a personal judgment of an individual's ability to carry out a series of activities required to achieve a certain type of performance, and a belief in his ability to organize and execute the execution process required to achieve a targeted performance. $[4,16]$.

\section{Job Satisfaction}

Job satisfaction was defined as an attitude that is influenced by the summation of all emotions that an individual experience in relation to his or her work, or a balance of favorability [5]. Other scholars called job satisfaction an emotional form of results obtained in the course of experiencing their duties, defined it as a function of satisfaction obtained or experienced through their duties, and regarded job satisfaction as closely related to their desires and values [6]. Job satisfaction is important because job satisfaction has a direct impact on the performance of members, and people who have positive feelings about their job talk positively about their organization outside, and those who are satisfied with their job can maintain smooth interpersonal relationships both inside and outside the organization [7].

\section{Experimental setup}

\section{Research Model and Research Hypothesis}

This study presents a model of research as shown in [Figure 1] to examine the effects of perceived emotional intelligence of members on self-efficacy and job satisfaction and to see what mediated role the self-efficacy of members of medical institutions plays. 


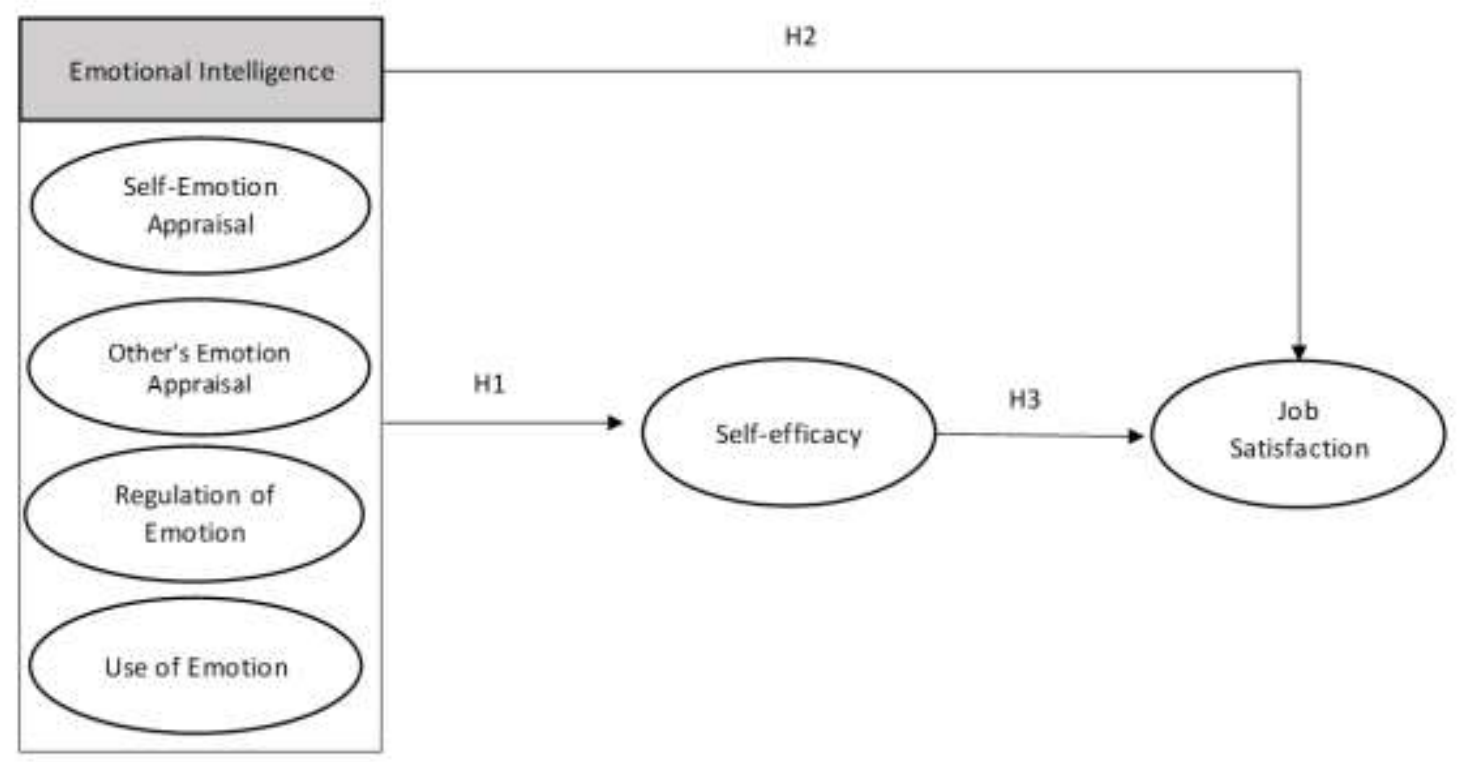

Figure 1. Research Model

\section{Emotional Intelligence and Self-Efficiency}

In a study on the emotional intelligence and self-efficacy of members, the emotional intelligence of the members has an important property that positively influences the motivation for the employee's job, so the members with high emotional intelligence are autonomous, positive and creative achievements in their jobs you can reap [8]. Self-efficacy has a positive relationship to the job satisfaction of the members, and emotional intelligence plays a positive role in self-development of the members' personal careers and achieving the organization's goals. Thus, self-efficacy is influenced by the perceived or perceived sensibilities of the members [9]. Therefore, based on previous studies, the following hypothesis was established with the inference that emotional intelligence will have a positive influence on self-efficacy.

H1. Members' perceived emotional intelligence will be positive for their self-efficacy.

H1-1 Self-emotion appraisal will be positive for self-efficacy.

H1-2 Other's emotion appraisal will be positive for self-efficacy.

H1-3 Regulation of emotion will be positive for self-efficacy.

H1-4 Use of emotion will be positive for self-efficacy.

\section{Emotional Intelligence and Job Satisfaction}

Looking at prior studies on emotional intelligence and job satisfaction, we confirmed that emotional intelligence of employees has a positive effect on job satisfaction regardless of the nature of the job, and that the higher the emotional intelligence, the higher the job satisfaction [10]. Emotional intelligence includes the ability to control emotions, so they try to positively convert and maintain their emotions even in negative emotional states, resulting in increased job satisfaction [11]. The higher the emotional intelligence of dental hygienists, the more effective the tissue is [12]. Therefore, based on previous studies, the hypothesis was established as follows.

H2. Members' perceived emotional intelligence will be positive for job satisfaction.

H2-1 Self-emotion appraisal will be positive for job satisfaction.

H2-2 Other's emotion appraisal will be positive for job satisfaction.

H2-3 Regulation of emotion will be positive for job satisfaction.

H2-4 Use of emotion will be positive for job satisfaction.

\section{Self-Efficacy and Job Satisfaction}

Research on self-efficacy has been mainly conducted in the field of organizational behavior, and it has been confirmed that it has a positive effect on job proficiency and job performance [13]. In addition, it was confirmed that the self-efficacy of the salesperson directly affects job satisfaction, and through this, it was found that the confidence and competence of the salesperson can be increased, thereby increasing the level of satisfaction with the job by themselves [14]. Therefore, based on previous studies, the hypothesis was established as follows.

H3. Self-efficacy will be positive for job satisfaction. 


\section{Mediating Effect of Self-Efficacy}

Self-efficacy is recognized as an important factor of human resources, and it can be predicted that high self-efficacy in service-oriented companies will have a positive effect on organizational performance. In addition, the mediating effect of self-efficacy did not have a significant effect in the relationship between emotional intelligence and innovative behavior of hotel staff, but it was confirmed that there was a significant influence through the indirect effect of self-efficacy [15]. Therefore, based on the results of these previous studies, it was possible to infer that emotional intelligence would directly affect job satisfaction, but indirectly mediate self-efficacy, so the hypothesis was set up as follows.

H4. Self-efficacy will have a mediating effect in relation to emotional intelligence and job satisfaction. H4-1 Self-efficacy will have a mediating effect in relation to self-emotion appraisal and job satisfaction. H4-2 Self-efficacy will have a mediating effect in relation to other's emotion appraisal and job satisfaction.

H4-3 Self-efficacy will have a mediating effect in relation to regulation of emotion and job satisfaction. H4-4 Self-efficacy will have a mediating effect in relation to use of emotion and job satisfaction.

\section{Population and Sample Characteristics}

To test the hypotheses set out in this study, an online survey was conducted on members of medical institutions (excluding doctors) in the Gyeonggi area. The measurement items consisted of 39 questions, and the measurement used a Likert five-point scale. The number of samples was collected in 148 parts, excluding 5 missing parts, and statistical analysis was performed using SPSS 22.0.

\section{Result discussions}

\subsection{Sample Characteristic}

The results of the census of demographics and general characteristics of the samples in this study are as follows [Table 1].

Table 1: Sample Characteristic

\begin{tabular}{|c|c|c|c|c|c|c|c|}
\hline variable & $\begin{array}{l}\text { Characteristi } \\
\text { c }\end{array}$ & Frequency & $\%$ & variable & Characteristic & Frequency & $\%$ \\
\hline \multirow{2}{*}{$\begin{array}{l}\text { Form of } \\
\text { establishment }\end{array}$} & Individual & 40 & 28 & \multirow{6}{*}{$\begin{array}{l}\text { service } \\
\text { period }\end{array}$} & $1 \sim 3$ & 40 & 28 \\
\hline & $\begin{array}{l}\text { A medical } \\
\text { firm }\end{array}$ & 103 & 72 & & $4 \sim 6$ & 48 & 33.6 \\
\hline \multirow{2}{*}{$\begin{array}{l}\text { hospital- } \\
\text { grade medical } \\
\text { institution }\end{array}$} & Hospital & 49 & $\begin{array}{l}34 . \\
3\end{array}$ & & $7 \sim 10$ & 30 & 21 \\
\hline & $\begin{array}{l}\text { General } \\
\text { hospital }\end{array}$ & 94 & $\begin{array}{l}65 . \\
7\end{array}$ & & $11 \sim 15$ & 17 & 11.9 \\
\hline \multirow[t]{2}{*}{ bed water } & $<100$ & 24 & $\begin{array}{l}22 . \\
5\end{array}$ & & $16 \sim 20$ & 8 & 5.6 \\
\hline & $100 \sim 300$ & 116 & $\begin{array}{l}16 . \\
8\end{array}$ & & $>20$ & 0 & 0 \\
\hline \multirow[t]{2}{*}{ Gender } & $\mathrm{M}$ & 54 & $\begin{array}{l}39 . \\
9\end{array}$ & \multirow[t]{3}{*}{ Position } & Staff & 40 & 28 \\
\hline & $\mathrm{F}$ & 86 & $\begin{array}{l}60 . \\
1\end{array}$ & & Team leader & 79 & 55.2 \\
\hline \multirow[t]{4}{*}{ Age } & $>20$ & 16 & $\begin{array}{l}11 . \\
2\end{array}$ & & Director & 24 & 16.8 \\
\hline & $>30$ & 16 & $\begin{array}{l}11 . \\
2\end{array}$ & \multirow[t]{3}{*}{$\begin{array}{l}\text { A service } \\
\text { departme } \\
\text { nt }\end{array}$} & $\begin{array}{l}\text { Administrativ } \\
\text { e } \\
\text { administratio } \\
\text { n department }\end{array}$ & 80 & 55.9 \\
\hline & $>40$ & 90 & $\begin{array}{l}62 . \\
9 \\
\end{array}$ & & $\begin{array}{l}\text { Nursing } \\
\text { Department }\end{array}$ & 38 & 26.6 \\
\hline & $>50$ & 21 & $\begin{array}{l}14 . \\
7\end{array}$ & & $\begin{array}{l}\text { Medical } \\
\text { Support } \\
\text { Division }\end{array}$ & 25 & 17.5 \\
\hline
\end{tabular}

\subsection{Feasibility and Reliability Analysis}

Factor analysis and reliability analysis were performed on the concept of composition of the research 
model. In the process of factor analysis, six questions with a factor value of 0.4 or less were removed, and the total variance described was $69.145 \%$. The variables were extracted in six equal numbers to the theoretical structure of the preceding study, and were named as self-emotion appraisal(SE), other's emotion appraisal(OE), regulation of emotion(RE), use of emotion(UE), self-efficacy(SF), and job satisfaction(JS), and reliability analysis was conducted for each variable. As a result of reliability analysis, the Cronbach' $\alpha$ value was found to be at an acceptable level (Cronbach' $\alpha>0.6$ ) as it was distributed in the range of .645 to .867 [Table 2].

Table 2: Feasibility and Reliability Analysis

\begin{tabular}{|c|c|c|c|c|c|c|}
\hline & \multicolumn{6}{|c|}{ Factor Loading } \\
\hline & 1 & 2 & 3 & 4 & 5 & 6 \\
\hline SF4 & .783 & .075 & .144 & -.050 & .269 & .028 \\
\hline SF5 & .736 & .372 & .001 & .266 & .040 & -.116 \\
\hline SF8 & .720 & .103 & .254 & .043 & .044 & $\begin{array}{l}.029 \\
\end{array}$ \\
\hline SF1 & .637 & .087 & .474 & .116 & -.044 & .011 \\
\hline SF6 & .535 & .267 & .417 & .024 & -.184 & .073 \\
\hline SF7 & .484 & .236 & .437 & .269 & -.423 & -.053 \\
\hline JS2 & .133 & .785 & .186 & -.069 & .263 & -.041 \\
\hline JS1 & .300 & .737 & .208 & .079 & .241 & -.049 \\
\hline JS4 & .310 & .688 & .078 & .262 & .010 & -.143 \\
\hline JS5 & -.006 & .669 & .468 & .163 & .139 & -.086 \\
\hline JS3 & .450 & .664 & -.053 & .066 & .195 & .075 \\
\hline JS7 & -.045 & .633 & .501 & .338 & -.005 & .016 \\
\hline UE3 & .155 & .234 & .767 & -.057 & .072 & .029 \\
\hline UE1 & .408 & .028 & .712 & .055 & .195 & -.026 \\
\hline UE2 & .200 & .159 & .602 & .309 & -.007 & .177 \\
\hline RE3 & -.203 & .065 & .118 & .798 & .167 & -.047 \\
\hline RE4 & .313 & .038 & .179 & .784 & .013 & .042 \\
\hline RE2 & .327 & .276 & -.010 & .684 & .004 & .010 \\
\hline OE2 & .049 & .153 & .004 & .074 & .845 & .021 \\
\hline OE1 & .155 & .247 & .345 & .031 & .721 & -.063 \\
\hline OE3 & .522 & .314 & .006 & .135 & .582 & .005 \\
\hline OE4 & -.164 & .439 & -.211 & .419 & .516 & .011 \\
\hline SE4 & -.010 & -.144 & .056 & .049 & .067 & .848 \\
\hline SE3 & -.101 & -.144 & .192 & .069 & -.011 & .731 \\
\hline SE2 & .073 & .154 & -.140 & -.114 & -.065 & .715 \\
\hline \multicolumn{7}{|c|}{ KMO $=.797 \quad$ Bartlett's $x^{2}=2069.605 p<.000$} \\
\hline Eigen value & 3.826 & 3.814 & 2.958 & 2.428 & 2.394 & 1.866 \\
\hline $\begin{array}{l}\text { Described } \\
\text { variance(\%) }\end{array}$ & 15.303 & 15.254 & 11.833 & 9.712 & 9.578 & 7.466 \\
\hline $\begin{array}{l}\text { Accumulated } \\
\text { variance(\%) }\end{array}$ & 15.303 & 30.557 & 42.39 & 52.102 & 61.68 & 69.145 \\
\hline Cronbach's $\alpha$ & 0.849 & 0.867 & 0.723 & 0.725 & 0.778 & 0.645 \\
\hline
\end{tabular}

\subsection{Correlation Analysis}

Correlation analysis was performed to confirm the correlation between variables, and the results are shown in [Table 3]. Except for self-emotion appraisal, all showed a significant relationship. In particular, the variables of self-efficacy and use of emotion show the strongest correlation with $(r=.635, p<.01)$, and the variables of self-efficacy and other's emotion appraisal are the weakest with $(r=.220, p<.01)$. Showing a relationship. Self-efficacy and job satisfaction $(\mathrm{r}=.538), \mathrm{p}<.01)$ the relationship between with was also highly correlated.

Table 3: Correlation analysis

\begin{tabular}{|l|l|l|l|l|l|l|}
\hline $\begin{array}{l}\text { measurement } \\
\text { variable }\end{array}$ & $\begin{array}{l}\text { Self-Emotion } \\
\text { Appraisal } \\
\text { (SE) }\end{array}$ & $\begin{array}{l}\text { Other's } \\
\text { Emotion } \\
\text { Appraisal(OE }\end{array}$ & $\begin{array}{l}\text { Regulation } \\
\text { of Emotion } \\
\text { (RE) }\end{array}$ & $\begin{array}{l}\text { Use of } \\
\text { Emotion } \\
\text { (UE) }\end{array}$ & $\begin{array}{l}\text { Self- } \\
\text { efficacy } \\
\text { (SF) }\end{array}$ & $\begin{array}{l}\text { Job } \\
\text { Satisfactio } \\
\text { n }\end{array}$ \\
\hline
\end{tabular}




\begin{tabular}{|c|c|c|c|c|c|c|}
\hline & & ) & & & & (JS) \\
\hline $\begin{array}{l}\text { Self-Emotion } \\
\text { Appraisal(SE) }\end{array}$ & 1 & & & & & \\
\hline $\begin{array}{l}\text { Other's } \\
\text { Emotion } \\
\text { Appraisal(OE) }\end{array}$ & -.033 & 1 & & & & \\
\hline $\begin{array}{l}\text { Regulation of } \\
\text { Emotion(RE) }\end{array}$ & -.006 & $.317^{* *}$ & 1 & & & \\
\hline $\begin{array}{l}\text { Use of } \\
\text { Emotion(UE) }\end{array}$ & .088 & $.259^{* *}$ & $.316^{* *}$ & 1 & & \\
\hline $\begin{array}{l}\text { Self- } \\
\text { efficacy(SF) }\end{array}$ & -.019 & $.220^{* *}$ & $.359 * *$ & $.635^{* *}$ & 1 & \\
\hline $\begin{array}{l}\text { Job } \\
\text { Satisfaction(JS } \\
\text { ) }\end{array}$ & -.082 & $.531^{* *}$ & $.402^{* *}$ & $.507^{* *}$ & $.538^{* *}$ & 1 \\
\hline
\end{tabular}

\subsection{Hypothesis test result}

[Table 4] is the result of analysis to test hypothesis 1 that the perceived emotional intelligence of members in the path relationship between the constituent concepts of the research model will have a positive effect on self-efficacy. Hypothesis 1-1 was rejected as it was found to have a negative effect on self-efficacy $(\beta=-.069, p=.286)$. Other's emotion appraisal $(\beta=.013, p=.849)$ did not affect self-efficacy, and hypothesis 1-2 was rejected. Regulation of emotion $(\beta=.169, \mathrm{p}=.016)$ was found to have a positive effect on self-efficacy, so hypothesis 1-3 was adopted. The use of emotions $(\beta=.584, p=.000)$ was found to have a positive effect on self-efficacy, so hypothesis 1-4 was adopted. The explanatory power of the regression model is presented as $42.0 \%$.

Table 4: Emotional Intelligence and Self-Efficiency

\begin{tabular}{|l|l|l|l|l|l|}
\hline Model & $\mathrm{B}$ & $\beta$ & $\mathrm{t}$-value & $\mathrm{p}$-value & VIF \\
\hline (constants) & 1.129 & & 2.580 & .011 & \\
\hline Self-Emotion Appraisal & -.078 & -.069 & -1.070 & .286 & 1.012 \\
\hline Other's Emotion Appraisal & .014 & .013 & .190 & .849 & 1.151 \\
\hline Regulation of Emotion & .165 & .169 & 2.430 & .016 & 1.190 \\
\hline Use of Emotion & .581 & .584 & 8.488 & .000 & 1.159 \\
\hline $\mathrm{R}^{2}=.436$, Adj $\mathrm{R}^{2}=.420, \mathrm{~F}=26.658(\mathrm{p}=<.001)$, Durbin-Watson $=2.039$ \\
\hline
\end{tabular}

[Table 5] is the result of analysis to test hypothesis 2 that the perceived emotional intelligence of members in the path relationship between the constituent concepts of the research model will have a positive effect on job satisfaction. Self-emotion appraisal analysis $(\beta=-.101, p=.111)$ was found to have a negative effect on job satisfaction, and hypothesis 2-1 was rejected. On the other hand, it is other's emotion appraisal $(\beta=.380, p=.000)$ and regulation of emotion $(\beta=.165, p=.017)$, use of emotion $(\beta=.365$, $\mathrm{p}=.000$ ) was found to represent a positive effect on job satisfaction. Therefore, hypothesis 2-2, hypothesis 2-3, and hypothesis 2-4 were all adopted. On the other hand, the results of analysis to test hypothesis 3 that self-efficacy will have a positive effect on job satisfaction are shown in [Table 6]. It was confirmed that self-efficacy $(\beta=.538, p=.000)$ had a positive effect on job satisfaction, and hypothesis 3 was adopted.

Table 5: Emotional Intelligence and Job Satisfaction

\begin{tabular}{|l|l|l|l|l|l|}
\hline Model & $\mathrm{B}$ & $\beta$ & $\mathrm{t}$-value & $\mathrm{p}$-value & VIF \\
\hline (constants) & .773 & & 1.696 & .092 & \\
\hline Self-Emotion Appraisal & -.122 & -.101 & -1.605 & .111 & 1.012 \\
\hline Other's Emotion Appraisal & .430 & .380 & 5.675 & .000 & 1.151 \\
\hline Regulation of Emotion & .171 & .165 & 2.423 & .017 & 1.190 \\
\hline Use of Emotion & .387 & .365 & 5.432 & .000 & 1.159 \\
\hline $\mathrm{R}^{2}=.462$, Adj $\mathrm{R}^{2}=.442, \mathrm{~F}=29.571(\mathrm{p}=<.001)$, Durbin-Watson $=1.935$ & \\
\hline
\end{tabular}


Table 6: Self-Efficacy and Job Satisfaction

\begin{tabular}{|l|l|l|l|l|}
\hline Model & $\mathrm{B}$ & $\beta$ & $\mathrm{t}$-value & $\mathrm{p}$-value \\
\hline (constants) & 1.960 & & 6.766 & .000 \\
\hline Self-efficacy & .574 & .538 & 7.583 & .000 \\
\hline $\mathrm{R}^{2}=.290$, Adj $\mathrm{R}^{2}=.285, \mathrm{~F}=57.508(\mathrm{p}=<.001)$, Durbin-Watson=1.850 \\
\hline
\end{tabular}

The analysis result [Table 7] shows that self-efficacy in relation to emotional intelligence and job satisfaction will have a mediated effect by executing multiple regression analysis to verify the mediated effect of the research model. In the first stage, self-emotion appraisal analysis $(\beta=-.069)$ negatively affects the parameter self-efficacy, while other's emotion appraisal analysis $(\beta=.013)$ does not have a significant effect. Regulation of emotion $(\beta=.169, \mathrm{p}<.05)$ and use of emotion $(\beta=.584, \mathrm{p}<.001)$ have a positive effect on self-efficacy. In step 2, self-emotion appraisal $(\beta=-.101)$ negatively affects job satisfaction, other's emotion appraisal $(\beta=.380, p<.001)$ and regulation of emotion $(\beta=.165, p<.05)$ The use of use of emotion $(\beta=.365, p<.001)$ has a positive effect on job satisfaction. In step 3 , self-emotion appraisal $(\beta=-.081)$ has a negative effect, other's emotion appraisal $(\beta=.376, p<.001)$ has a positive effect, and regulation of emotion $(\beta=.117)$ has a significant effect. It did not have one effect, and use of emotion $(\beta=.198, p<.05)$ has a positive effect. The parameter of self-efficacy $(\beta=.286, p<.001)$ has a positive effect on job satisfaction. Therefore, in the third stage of testing the mediating effect, the self-efficacy as a parameter affects job satisfaction, and only the lower factor use of emotion among the independent variable emotional intelligence has a significant effect on job satisfaction, so it can be said that it is partially mediated.

Table 7: Mediating Effect of Self-Efficacy

\begin{tabular}{|c|c|c|c|c|c|c|c|c|c|}
\hline \multirow{3}{*}{ Model } & \multicolumn{3}{|c|}{ step1 } & \multicolumn{3}{|c|}{ step2 } & \multicolumn{3}{|c|}{ step3 } \\
\hline & \multicolumn{3}{|c|}{ Self-efficacy } & \multicolumn{3}{|c|}{ Job Satisfaction } & \multicolumn{3}{|c|}{ Job Satisfaction } \\
\hline & B & $\beta$ & $\mathrm{t}$ & $\mathrm{B}$ & $\beta$ & $\mathrm{t}$ & $\mathrm{B}$ & $\beta$ & $\mathrm{t}$ \\
\hline (constants) & 1.129 & & 2.580 & .773 & & 1.696 & .429 & & .957 \\
\hline $\begin{array}{l}\text { Self-Emotion } \\
\text { Appraisal }\end{array}$ & -.078 & -.069 & $\begin{array}{l}- \\
1.070\end{array}$ & -.122 & -.101 & $\begin{array}{l}- \\
1.605\end{array}$ & -.099 & -.081 & -1.340 \\
\hline $\begin{array}{l}\text { Other's } \\
\text { Emotion } \\
\text { Appraisal }\end{array}$ & .014 & .013 & .190 & .430 & $.380^{* * *}$ & 5.675 & .426 & $.376^{* * *}$ & 5.855 \\
\hline $\begin{array}{l}\text { Regulation of } \\
\text { Emotion }\end{array}$ & .165 & $.169^{*}$ & 2.430 & .171 & $.165^{*}$ & 2.423 & .121 & .117 & 1.747 \\
\hline Use of Emotion & .581 & $.584^{* * *}$ & 8.488 & .387 & $.365^{* * *}$ & 5.432 & .210 & $.198^{*}$ & 2.488 \\
\hline Self-efficacy & & & & & & & .305 & $.286^{* * *}$ & 3.585 \\
\hline $\mathrm{R}^{2}$ & \multicolumn{3}{|l|}{.42} & \multicolumn{3}{|l|}{.446} & \multicolumn{3}{|l|}{.49} \\
\hline $\mathrm{F}$ & \multicolumn{3}{|c|}{$26.658^{* * *}$} & \multicolumn{3}{|c|}{$29.571^{* * *}$} & \multicolumn{3}{|c|}{$28.259^{* * *}$} \\
\hline Durbin-Watson & \multicolumn{3}{|l|}{2.039} & \multicolumn{3}{|c|}{1.935} & \multicolumn{3}{|c|}{1.840} \\
\hline
\end{tabular}

$* \mathrm{p}<0.05^{* *} \mathrm{p}<0.01 * * * \mathrm{p}<0.001$

The results of hypothesis verification through path analysis of this study are shown in [Figure 2], and the results of empirical analysis of hypotheses set according to the research model can be confirmed. 


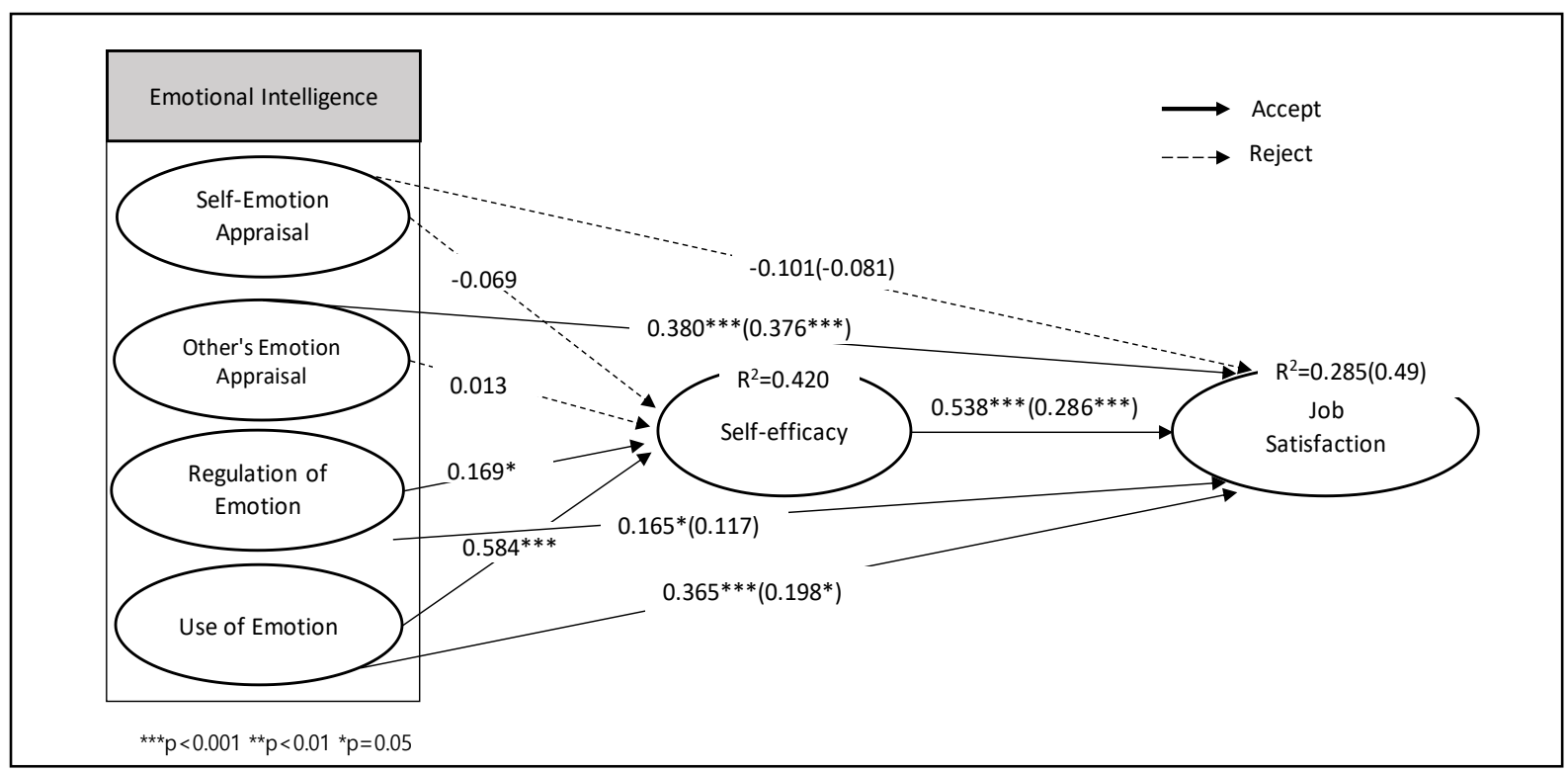

Figure 2. Path hypothesis test result

\section{Conclusions}

This study has validated the effects of perceived emotional intelligence on self-efficacy and job satisfaction of members of medical institutions. Also, in relation to emotional intelligence and job satisfaction, selfefficacy could be checked for a mediated effect. The results of the study are summarized as follows. First, self-emotion appraisal, a sub-factor of perceived emotional intelligence among members of medical institutions, was negatively affecting self-efficacy and job satisfaction. This means that it is not easy to confidently push ahead with a given task and problem-solving because it is not clear where members understand their feelings and feelings. The negative impact seems to be that due to the nature of the work, the sense of duty that the customer's position should be considered first, which tends to suppress emotions rather than understanding them themselves. Second, the sub-factor of perceived emotional intelligence among members of medical institutions, other's emotion appraisal, has not affected selfefficacy and has a positive effect on job satisfaction. Because of the nature of the work, efforts to understand the customer's position and satisfy the medical service are made to understand other people's feelings, and although they are satisfied with their duties, they seem to lack individual beliefs and goal consciousness. Third, regulation of emotion, a sub-factor of perceived emotional intelligence among members of medical institutions, appears to have significant effects on self-efficacy and job satisfaction. This is believed to have been shown as an environmental characteristic that provides professional services only when the ability to control and control emotions on its own when responding to customers. Fourth, use of emotion, a sub-factor of perceived emotional intelligence by members of medical institutions, has been shown to have a significant effect on self-efficacy and job satisfaction. This can be confirmed that members who control their emotions well and always strive to achieve their goals with a positive mind have high self-efficacy and job satisfaction Fifth, it was found that self-efficacy had a positive effect on job satisfaction. This can be interpreted that members with higher confidence in their work, achievement of goals, overcoming problems, and positive evaluation show higher satisfaction with their duties. Finally, it was possible to confirm the partial mediation only in the use of emotions, seeing the mediating effect of self-efficacy between emotional intelligence and job satisfaction. In this study, although some results differ slightly from those of prior studies, the higher the emotional intelligence, the more positive the effect on self-efficacy. In addition, when the self-efficacy was high, the positive effect on job satisfaction and the results were confirmed through verification. The implications of this study will first be to develop a program that can be shared within the organization to enhance the perceived emotional intelligence of its members. Second, the use of emotional intelligence could be very useful in checking the organization from a long-term perspective and finding organizational improvements and solutions to vitalize the organization. Third, as members with high emotional intelligence elicit empathy and increase self-efficacy, it is effective in indirectly motivating them to take action to achieve their goals, thus improving job satisfaction and positively affecting performance improvement. Medical institutions always deal with human issues due to a lack of manpower. Therefore, if you can manage your emotions, understand other people's emotions, and achieve harmony by empathizing with them, your work life will be satisfactory for members. While this study looked at the universal results of medical institution 
members, it had a limitation that it did not reflect the characteristics of each position and profession. Therefore, research that embodies the method of research is thought to be necessary.

\section{Acknowledgements}

This research was financially supported by Han sung University.

\section{References}

[1] Goleman, Daniel. Working with emotional intelligence. Bantam, 1998.

[2] Salovey, Peter, and John D. Mayer. "Emotional intelligence." Imagination, cognition and personality 9 , no. 3 (1990): 185-211.

[3] Bandura, A. (1997). Self efficacy: The exercise of control. New York: Freeman.

[4] Bandura, Albert. "Social foundations of thought and action." Englewood Cliffs, NJ 1986 (1986): 23-28.

[5] Smith Henry, C. "Psychology of Industrial Behavior." (1955): 114-115.

[6] Kim, Young-Hun, and Youngchul Chang. "A Study on the Moderating Effects of Shared Leadership on the Relationship between Types of Organizational Culture and Organizational Commitment, Job Satisfaction-A Focus on Company'P." Journal of the Korea Academia-Industrial cooperation Society 14, no. 12 (2013): 6173-6185

[7] Cheol-Woo Lee. (2015). The Effect of Specialty Hospital CEO Leadership Style on Hospital Orga nizational Effectiveness and Customer Orientation. Doctoral dissertation. Graduate School of Gach on University. Korea.

[8] Cooper, Robert K., and A. Coautor Sawaf. Executive EQ: Emotional intelligence in leadership and organization. No. 658.409 C7841c Ej. 1 000003. GROSSET,, 1997.

[9] Jung Eun Jung. (2015). The Effects of Emotional Leadership upon Self-Efficacy and Organization al Performance: Focusing on Moderating Effects of Emotional Intelligence. Doctoral dissertation. Graduate School Kyonggi University. Korea.

[10] Wong, Chi-Sum, and Kenneth S. Law. "The effects of leader and follower emotional intelligence on performance and attitude: An exploratory study." The leadership quarterly 13, no. 3 (2002): 243-274.

[11] Carmeli, Abraham. "The relationship between emotional intelligence and work attitudes, behavior and outcomes." Journal of managerial Psychology (2003).

[12] Kim, Young-Im. "A Study on effects of emotional labor and emotional intelligence of dental hygienist on organizational effectiveness." Journal of the Korea Academia-Industrial cooperation Society 20, no. 9 (2019): 390-396.

[13] Martocchio, Joseph J., and Timothy A. Judge. "Relationship between conscientiousness and learning in employee training: Mediating influences of self-deception and self-efficacy." Journal of Applied Psychology 82, no. 5 (1997): 764.

[14] McDonald, Tracy, and Marc Siegall. "The effects of technological self-efficacy and job focus on job performance, attitudes, and withdrawal behaviors." The Journal of Psychology 126, no. 5 (1992): 465475.

[15] Hee Su Kim, Gyu Tae Lee. (2015). “The Influence of Hotel Staff s Emotional Intelligence on Innovative Behavior: The Mediating Effect of Self-efficacy." International Journal of Tourism and Hospitality Research 29(12), 91-103.

[16] Allen N. Maroma;Dolly P. Maroma. (2017). "Personal and Work Related Correlates of Professional Self-Efficacy of Teachers in the Bachelor in Industrial Technology Program of the Bulacan State University." International Journal of Emerging Multidisciplinary Research, 1(1), 63-68. DOI: 10.22662/IJEMR.2017.1.1.063 